\title{
James Helgeson, The lying mirror. The first-person stance and sixteenth-century writings
}

\section{Martina Airoldi}

\section{(2) OpenEdition}

1 Journals

\section{Edizione digitale}

URL: https://journals.openedition.org/studifrancesi/3039

DOI: 10.4000/studifrancesi.3039

ISSN: 2421-5856

\section{Editore}

Rosenberg \& Sellier

\section{Edizione cartacea}

Data di pubblicazione: 1 juillet 2013

Paginazione: 349-440

ISSN: 0039-2944

\section{Notizia bibliografica digitale}

Martina Airoldi, «James Helgeson, The lying mirror. The first-person stance and sixteenth-century

writings», Studi Francesi [Online], 170 (LVII | II) | 2013, online dal 30 novembre 2015, consultato il 02 février 2023. URL: http://journals.openedition.org/studifrancesi/3039; DOI: https://doi.org/10.4000/ studifrancesi.3039

\section{Questo documento è stato generato automaticamente il 2 février 2023.}

\section{(c) 9 (1) $\Theta$}

Creative Commons - Attribuzione - Non commerciale - Non opere derivate 4.0 Internazionale - CC BYNC-ND 4.0

https://creativecommons.org/licenses/by-nc-nd/4.0/ 


\section{James Helgeson, The lying mirror. The first-person stance and sixteenth- century writings}

Martina Airoldi 


\section{NOTIZIA}

JAMES HELGESON, The lying mirror. The first-person stance and sixteenth-century writings, Genève, Droz, 2012, pp. 334.

Il volume offre un interessante studio su un tema caro alla critica: la scrittura in prima persona. Suddiviso in due parti, la prima, più teorica, indaga i significati di intenzionalità e identificazione, la seconda, più analitica, si sofferma, in particolare, sull'analisi di alcuni testi di Erasmo e Rabelais, attraverso argomentazioni costruite sui concetti di intenzionalità da un lato e di azione poetica dall'altro, secondo richiami costanti alle categorie di autorialità e intenzionalità. Inoltre, l'A. propone una nuova prospettiva investigativa. Si tratta cioè di presentare un percorso critico che vada al di là dello status del sé, affinché la focalizzazione analitica sia costruita sulla presunta intenzionalità del testo. In questa sua indagine, dunque, l'A. sceglie di abbandonare lo studio del sé, secondo le impostazioni critiche codificate di natura storico-ontologica, per avventurarsi lungo un itinerario investigativo che faccia del testo l'asse centrale delle analisi. L'intenzionalità del testo, argomento fondante di questo studio, è per Helgeson da intendersi come ciò a cui il testo stesso tenderebbe. Come quell'etica di scrittura in prima persona, che si costruisce su due elementi principali: la falsità e la disonestà. Partendo dal concetto chiave di dissimulazione, l'A. propone le analisi di alcuni passaggi di testi francesi e olandesi del XVI secolo. Si tratta perlopiù di poesie, cronache e lettere pubbliche, che gli consentono di interrogarsi sull'etica della scrittura in prima persona. Sono poi indagate questioni legate alla verità, all'allegoria e al coinvolgimento politico. 